\title{
Study on Teachers Pressure of National Model Higher Vocational College Jian Yong ${ }^{1,}$ a * \\ ${ }^{1}$ Weihai Vocational College, Shandong, China \\ a1541545319@qq.com
}

Keywords: AHP; Teacher pressure; Vocational colleges.

\begin{abstract}
At present, there are a total of 77 types of vocational colleges in Shandong Province, how is occupational stress of the National Model Higher Vocational College Teachers? Are they generally under higher occupational stress and how do they relieve occupational stress? Society, schools, teachers themselves should take measures to ease the National Model Higher Vocational College Teachers' professional pressure. As a national demonstrative higher vocational colleges teacher, whether from their own experience or from the surrounding colleagues feeling, we deeply feel it is imperative to strengthen the study problems of teachers occupational stress in National Demonstrative Higher Vocational College.
\end{abstract}

\section{Introduction}

The rapid development of higher vocational education has not only brought unprecedented opportunities of development for the majority of the national model higher vocational colleges teachers, but also brought great challenges to the vast number of national model vocational college teachers. At present, there are a total of 77 types of vocational colleges in Shandong Province, how is occupational stress of the national model of Higher Vocational College Teachers in the current situation? Are they generally under higher occupational stress and how do they relieve occupational stress? Society, schools, teachers themselves should take measures to ease the national model of Higher Vocational College Teachers' professional pressure? As a national demonstrative higher vocational colleges teacher, whether from their own experience or from the surrounding colleagues feeling, we deeply feel it is imperative to strengthen the study of teachers occupational stress problems of National Demonstrative Higher Vocational College.

So our research group hold enthusiasm, use education, psychology, management science, statistics and other professional knowledge to investigate and study the general characteristics and occupational stress in gender, age, education background, seniority, job title, teaching subjects, average week of class, whether having a training course, whether as a class teacher, whether being a dual qualification teachers.

\section{Establish Evaluation Index System}

We aim to slow teachers' occupational stress in Higher Vocational Colleges from the five aspects: supporting system, own growth, title assessment, treatment improvement, professional status to establish evaluation index system as the ultimate goal.

\section{The Composition of Teachers' Occupational Stress Index System}

The index system of teachers' occupational stress is composed of five aspects: support system, self growth, treatment promotion, professional status, self quality. Each level indicator is divided into four or five different two level indicators, and determines the weight of the two indicators. See fig.1.

Support system includes family factors, school factors and social factors.

Self growth includes academic qualifications, professional title evaluation, in-service training and the quality of the double division. 
Treatment promotion includes salary level, bonuses, benefits, holidays.

Professional status includes professional importance, popularity, professional ability, employment prospects.

Self quality includes anti pressure, teaching attitude, teaching ability and organization ability.

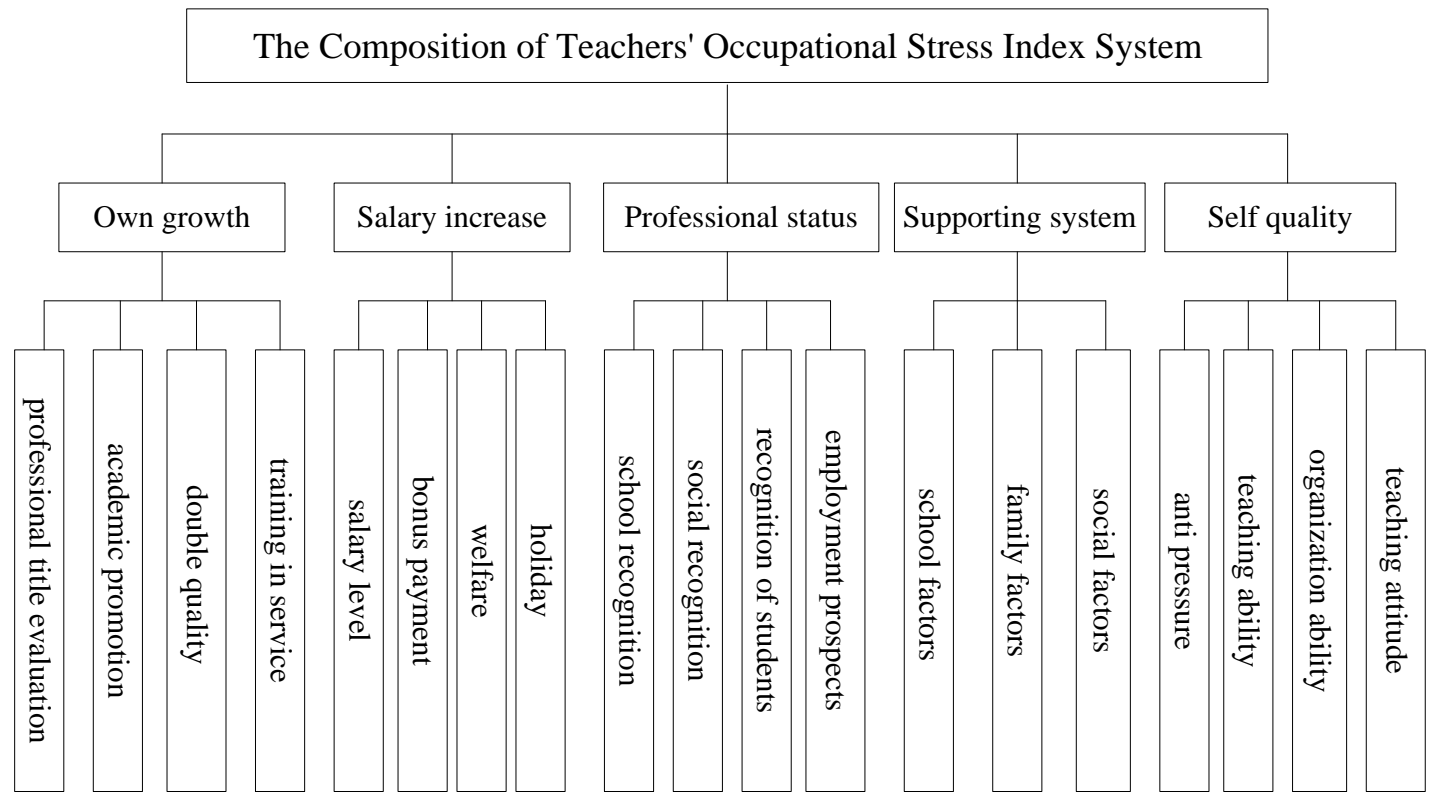

Figure 1. The composition of teachers' occupational stress index system

\section{Establish Judgment Matrices}

Calculate the weight of the indicators, the results are as follows:

Establish Judgment Matrices of the first indicator index.

$\left[\begin{array}{ccccc}1 & 3 & 5 & 6 & 7 \\ 1 / 3 & 1 & 2 & 3 & 4 \\ 1 / 5 & 1 / 2 & 1 & 2 & 3 \\ 1 / 6 & 1 / 3 & 1 / 2 & 1 & 2 \\ 1 / 7 & 1 / 4 & 1 / 3 & 1 / 2 & 1\end{array}\right]$

The result of calculation is as follow:

$\mathrm{W}=(0.5209,0.2175,0.1296,0.0805,0.0515)$

$\lambda_{\text {max }}=5.0851, \quad \mathrm{CI}=0.02127, \mathrm{CR}=0.0190<0.1$

Establish Judgment Matrices of own growth 


$$
\left[\begin{array}{cccc}
1 & 3 & 4 & 5 \\
1 / 3 & 1 & 3 & 4 \\
1 / 4 & 1 / 3 & 1 & 3 \\
1 / 5 & 1 / 4 & 1 / 3 & 1
\end{array}\right]
$$

The result of calculation is as follow:

$\mathrm{A} 1: \mathrm{W}=(0.5287,0.2687,0.1343,0.0683)$,

$\mathrm{A} 1: \lambda_{\max }=4.1807, \mathrm{CI}=0.0602, \mathrm{CR}=0.0669<0.1$

Establish Judgment Matrices of salary increase.

$\left[\begin{array}{cccc}1 & 3 & 4 & 5 \\ 1 / 3 & 1 & 2 & 3 \\ 1 / 4 & 1 / 3 & 1 & 2 \\ 1 / 5 & 1 / 4 & 1 / 3 & 1\end{array}\right]$

The result of calculation is as follow:

$\mathrm{A} 2 \mathrm{~W}(2)=(0.4668,0.2776,0.1603,0.0953)$,

$\mathrm{A} 2: \lambda_{\max }=4.0310, \mathrm{CI}=0.0103, \mathrm{CR}=0.0115<0.1$

Establish Judgment Matrices of professional status.

$\left[\begin{array}{cccc}1 & 3 & 4 & 5 \\ 1 / 3 & 1 & 2 & 3 \\ 1 / 4 & 1 / 2 & 1 & 2 \\ 1 / 5 & 1 / 3 & 1 / 2 & 1\end{array}\right]$

The result of calculation is as follow:

A3: W $(3)=(0.4668,0.2776,0.1603,0.0953)$,

$\mathrm{A} 3: \lambda_{\text {max }}=4.0310, \mathrm{CI}=0.0103, \mathrm{CR}=0.0115<0.1$

Establish Judgment Matrices of supporting system. 


$$
\left[\begin{array}{ccc}
1 & 2 & 3 \\
1 / 2 & 1 & 2 \\
1 / 3 & 1 / 2 & 1
\end{array}\right]
$$

The result of calculation is as follow:

$\mathrm{A} 4: \mathrm{W}(4)=(0.5396,0.2970,0.1634)$

A4: $\lambda_{\text {max }}=3.0092, \mathrm{CI}=0.0046, \mathrm{CR}=0.0079<0.1$

Establish Judgment Matrices of self quality

$$
\left[\begin{array}{cccc}
1 & 3 & 4 & 5 \\
1 / 3 & 1 & 3 & 4 \\
1 / 4 & 1 / 3 & 1 & 2 \\
1 / 5 & 1 / 4 & 1 / 2 & 1
\end{array}\right]
$$

The result of calculation is as follow:

$\mathrm{A} 5: \mathrm{W}(5)=(0.5318,0.2702,0.1221,0.0760)$

$\mathrm{A} 5: \lambda_{\max }=4.1142, \mathrm{CI}=0.0381, \mathrm{CR}=0.0423<0.1$

Finally, we test the consistency according to the principal.

\section{Conclusion}

In the teacher's occupational stress indicator system, support system, own growth, treatment, professional status, own quality, own growth has the highest weight. In the second level indicators, support system includes family factors, school factors, social factors, family factors has the highest weight. In their own growth, the professional title assessment has brought the greatest pressure to teachers, and the weight is the highest. Treatment improvement includes the level of wages, bonuses, welfare, holidays, and the wage level has a greater weight. In the professional status, the importance of professional is particularly important. In their quality, the weight of the anti pressure is the biggest.

\section{References}

[1] Discretion and bias in performance evaluation: the impact ofdiversity and subjectivity Volume [J]:30, Issue: 1, January, 2005, pp.67-78

[2] European Management Journal Volume [J]:21, Issue: 3, June, 2003. pp323-337

[3] http://thequalityportal.com/q_ahp.htm. Retrieved 2007-08-21.

[4] European Management Journal Volume [J]:21, Issue: 3, June, 2003. pp323-337 